\title{
INFLUENCE OF THE ANNEALING TEMPERATURE ON THE HARDNESS OF THE BUILT-UP EDGE OF MEDIUM CARBON STEEL
}

\author{
Wojciech PRESZ \\ Warsaw University of Technology, Institute of Manufacturing Technologies, Warsaw, Poland, EU, \\ wojciech.presz@pw.edu.pl
}

https://doi.org/10.37904/metal.2021.4143

\begin{abstract}
In metal forming processes, in some cases, galling occurs, which results in the formation of built-up edges on the surface of the tool. They usually damage the outer layer of the workpiece. The aim of the work is to broaden the knowledge about the structure and mechanisms of the formation of the build-ups structure. In this case, it concerns the build-up produced on the NC6 steel tool in the process of drawing the steel 30 strip at an elevated temperature. At a special stand enabling the process temperature change, the temperature of the greatest tendency to galling in dry friction conditions was determined at $620^{\circ} \mathrm{C}$. As a result of the research, the annealing temperature of the built-up material was determined at $500^{\circ} \mathrm{C}$. It was noted that the build-up formed at $620^{\circ} \mathrm{C}$ has a hardness more than twice as high as the same build-up annealed for $1 \mathrm{~h}$ at approximately similar temperature, $600{ }^{\circ} \mathrm{C}$. The difference is due to the differences in the dynamics of the processes. The process of the build-up leads to the formation of a highly deformed supercooled structure which reaches the state of equilibrium during quasi-static annealing. The energy stored in the supercooled structure of the buildup during annealing at a relatively low temperature of $400{ }^{\circ} \mathrm{C}$ activates the recovery process, reducing the hardness by $30 \%$. Structural investigations have shown that the resulting build-up has a streak structure, probably created in the process of shearing successive layers of material. In build-up edge, the more strengthened layers alternate between layers with a lower degree of deformation.
\end{abstract}

Keywords: Metal forming, build-ups, microstucture, warm-forming

\section{INTRODUCTION}

Wherever sliding contact of solids occurs, i.e. in virtually all fields of technology, one should take into account the possibility of unfavorable wear phenomena related to the phenomenon of adhesion [1]. They lead to an increase in the coefficient of friction, damage to the surface and the deposit of softer material on the harder material [2]. This phenomenon takes many forms [3], but only one of them is called galling. The accepted definition is: A form of surface damage arising between sliding solids, distinguished by macroscopic, usually localized, roughening, and the creation of protrusions above the original surface; it is characterized by plastic flow and may involve material transfer. Tools in metal forming processes are particularly exposed to this severe form of adhesive wear [4]. The unfavorable tribological conditions occurring here, such as high pressures, surface growth of the deformed material and low relative speeds favor the development of this process. This is especially the case at forming at elevated temperatures [5]. In these processes, counteracting the galling phenomenon becomes one of the main technological problems. Particularly unfavorable lubrication conditions occur in microforming $[6,7]$ and micro-blanking processes [8] which have recently become of particular interest. In order to eliminate or at least reduce the tendency to galling, many different methods are used, such as surface [9] and sructure [10] modification of the tool, surface topography control [11,12] and even tool vibration at different frequencies [13,14]. Galling also increases the forces of the process [15] and can scratch the surface of the tool. It is possible because the hardness of the built-up edge even made of soft material, is very 
high and is caused by large deformations that arise during its formation. Much of the work on galling in the literature has been concerned with the qualification of galling,[16] with much lover being produced on the buildup structure [17] and galling initiation in micro-scale [18]. From the published works, we learn that the buildups generated in the galling process have a layered structure [17]. It should be noted that the phenomenon of the formation of the built-up structure is similar to one of the methods of producing ultra-fine-grained materials. Namely: Incremental Equal Channel Angular Pressing (I-ECAP) [19]. In both cases, successive layers of material are sheared without loss of cohesion, which leads to the fragmentation of the structure and great strain hardening. The aim of this work is to broaden the knowledge about the structure of the build-up and the mechanisms of its formation. In this case, it concerns the build-up produced in the process of drawing the steel 30 strip with a NC6 steel tool under warm working conditions.

\section{MATERIAL AND METHODS}

The research program included:

- determining the optimal conditions for the formation of built-up edges,

- creating build-ups,

- determination of the influence of temperature on the microhardness of the build-up edge and determination of the annealing temperature of its material,

- $\quad$ structural analysis of created build-ups.

\subsection{Materials}

Steel 30 is a steel with a carbon content of 0.27 to $0.34 \%$. At such a concentration of carbon, pearlite appears in the steel structure and the steel has a ferritic-pearlitic structure. NC 6 steel is a cold work tool steel with high resistance to abrasion and tempering. The chemical composition of both materials is shown in Table 1.

Table 1 Chemical composition of the materials used

\begin{tabular}{|c|c|c|c|c|c|c|c|c|c|}
\hline \multirow[b]{2}{*}{ Element } & \multicolumn{9}{|c|}{ Strip - Steel 30 (149 HB) } \\
\hline & C & $\mathrm{Mn}$ & $\mathrm{Si}$ & $\mathrm{Cr}$ & $\mathbf{N i}$ & $\mathbf{P}$ & Mo & $\mathbf{V}$ & $\mathbf{S}$ \\
\hline \multirow{3}{*}{ Range (wt\%) } & $\begin{array}{l}0.27- \\
0.35\end{array}$ & $\begin{array}{l}0.50- \\
0.80\end{array}$ & $\begin{array}{l}0.17- \\
0.35\end{array}$ & $\begin{array}{l}\text { Max } \\
0.25\end{array}$ & Max 0.25 & Max 0.04 & - & - & $\operatorname{Max} 0.04$ \\
\hline & \multicolumn{9}{|c|}{ Tool - Steel NC6 (60 HRC) } \\
\hline & $\begin{array}{l}1.30- \\
1.45\end{array}$ & $\begin{array}{l}0.40- \\
0.70\end{array}$ & $\begin{array}{l}0.15- \\
0.40\end{array}$ & $\begin{array}{l}1.30- \\
1.65\end{array}$ & $\operatorname{Max} 0.35$ & Max 0.03 & $\begin{array}{l}\text { Max } \\
0.20\end{array}$ & $\begin{array}{l}0.10- \\
0.25\end{array}$ & $\operatorname{Max} 0.03$ \\
\hline
\end{tabular}

\subsection{Creation of build-ups}

The process of the formation of the built-up edge of steel 30 was carried out on a machine for the galling phenomenon, the diagram of which is shown in Figure 1a.

The steel 30 band -1 is guided by the roller -2 and pressed by the roller -3 , against the drive pulley -4 , which gives it a constant speed of $V=1 \mathrm{~m} / \mathrm{s}$. The strip is resistively heated in the section between the driving roller and the slider -5 . The tool -6 is temporarily pressed against the strip by means of the knee system -7 during one revolution of the wheel -8 . The pressing force is sufficient to plasticize the strip and temporarily carry out the drawing process in dry friction condition, which results in the formation of built-up edge. The temperature of the moving is regulated by a step change in the voltage of the transformer, which heats up to $450,530,620$, 740 , or $870^{\circ} \mathrm{C}$. A number of tests were carried out on the basis of which it was found that the largest deposits are formed at the temperature of $620^{\circ} \mathrm{C}$. The friction path of the NC6 tool on the steel strip 30 in this process is $35 \mathrm{~mm}$. 


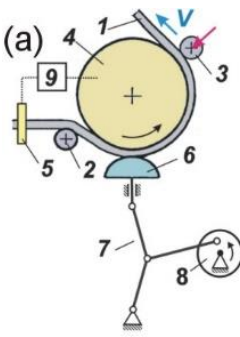

(b)

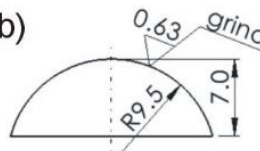

(c)

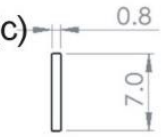

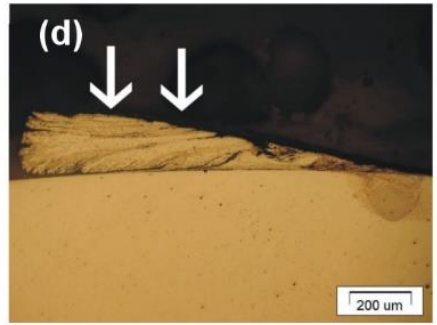

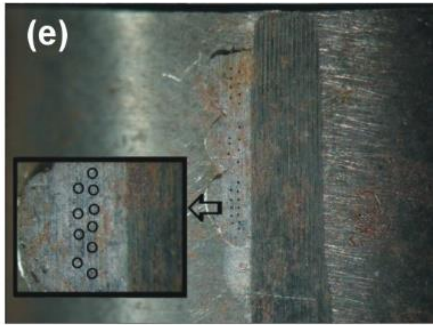

Figure 1 Experimental tests: (a) scheme of the build-up stand - description in the text, (b) dimensions of the tool and (c) strip, (d) view of the tool cross-section with built-up edge, (e) view of the ground surface of the build-up with marked measurement places

\subsection{Rolling process off the strip}

As delivered, the strip was subjected to extreme cold rolling to determine the degree of hardening that can be achieved. The strip was thinned to a thickness of $0.08 \mathrm{~mm}$, achieving the equivalent deformation $\varepsilon=2$.

\subsection{Heat treatment - annealing}

On the basis of preliminary tests, the annealing of the build-up was started at the temperature of $400{ }^{\circ} \mathrm{C}$, and then the temperature was increased successively by $50^{\circ} \mathrm{C}$. The build-up was annealed in a vacuum furnace for 1 hour at the following temperatures: $400,450,500,550,600$ and $650^{\circ} \mathrm{C}$.

\section{THE RESULTS OF THE EXPERIMENTS}

\subsection{Microhardness tests}

The built-up surface is very uneven and it is difficult to obtain reliable microhardness results on it. Therefore, it was decided to grind the surface to a depth of approx. $20 \mu \mathrm{m}$ in conditions of increased cooling, eliminating the possible influence of the grinding temperature on the hardness. Hardness was measured on its horisontaly ground surface (Figure 1e). The results were presented for two samples marked as: $S p . A$ and $S p$. B. The graphic interpretation of the hardness test results on the surface of the built-up edge, according to Figure 1d, is shown in Figure 2.
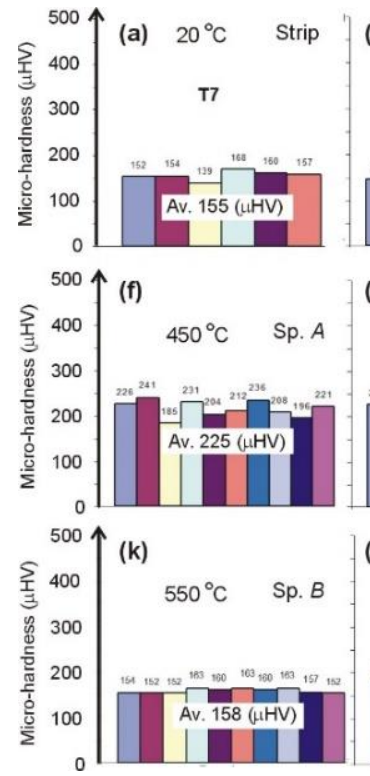

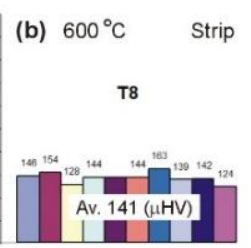

(g)
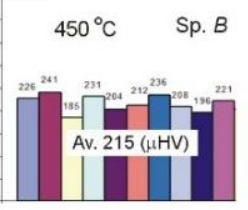

(I)

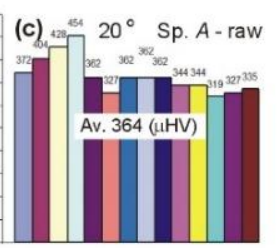

(h)

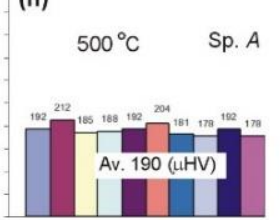

( $\mathrm{m})$

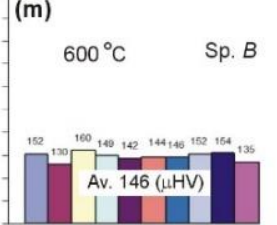

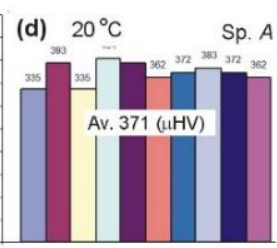

(i)

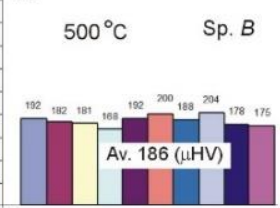

(n)

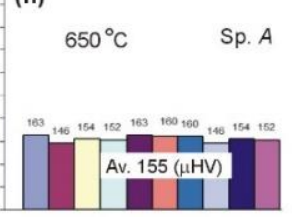

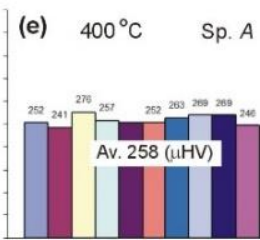

(i)

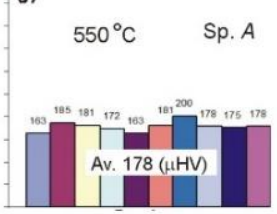

(o)

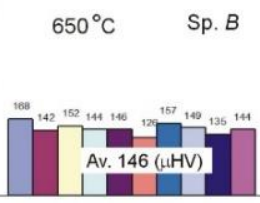

Figure 2 Hardness test results after different annealing temperatures: (a), (b) strips; (c) - (o) accretion on the upper surface (Figure 1c) 
This figure also shows the results of the strip microhardness test in the delivery condition (Figure 2a) and after annealing (Figure 2b). The averaged results from the tests carried out are presented in Table 2. On their basis, a graph (Figure 3) was prepared and the recrystallization temperature of the build-up material was determined at $500{ }^{\circ} \mathrm{C}$. Graphical interpretation of the hardness test results on the ground surface of the built-up edge according to Figure 1d is shown in Figure 2. This figure also shows the results of the strip microhardness test in the delivery condition Figure $\mathbf{2} \mathbf{a}$ and after annealing - Figure $\mathbf{2 b}$. The averaged results from the performed tests are presented in Table 2. On their basis, a diagram was

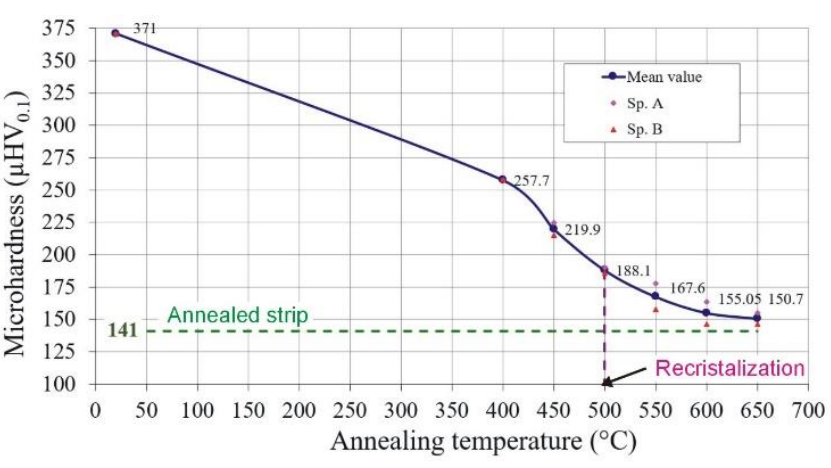

Figure 3 The build-up microhardness as a function of annealing temperature, the horizontal line shows the strip hardness and the vertical line shows the recrystallization temperature prepared (Figure 3) and the recrystallization temperature of the build-up material was determined as $500{ }^{\circ} \mathrm{C}$.

Table 2 Microhardness of annealed build-ups

\begin{tabular}{|l|c|c|c|c|c|c|}
\hline Annealing temperaturę ( $\left.{ }^{\circ} \mathbf{C}\right)$ & $\mathbf{4 0 0}$ & $\mathbf{4 5 0}$ & $\mathbf{5 0 0}$ & $\mathbf{5 5 0}$ & $\mathbf{6 0 0}$ & $\mathbf{6 5 0}$ \\
\hline Sp. $\boldsymbol{A}(\boldsymbol{\mu H V})$ & 257.7 & 224.5 & 190.2 & 177.6 & 163.7 & 155.0 \\
\hline Sp. $\boldsymbol{B}(\boldsymbol{\mu H V})$ & $\mathrm{X}$ & 215.2 & 186.0 & 157.6 & 146.4 & 146.3 \\
\hline
\end{tabular}

\subsection{Structural research}

The strip samples and tools with the produced and annealed build-up were cut in a plane perpendicular to the contact surface and parallel to the direction of the strip movement. Then metallographic specimens were performed. Selected results are shown in Figure 4. In Figures $\mathbf{4 b}, \mathbf{c}, \mathbf{d}$, the imprints after the microhardness test are visible.
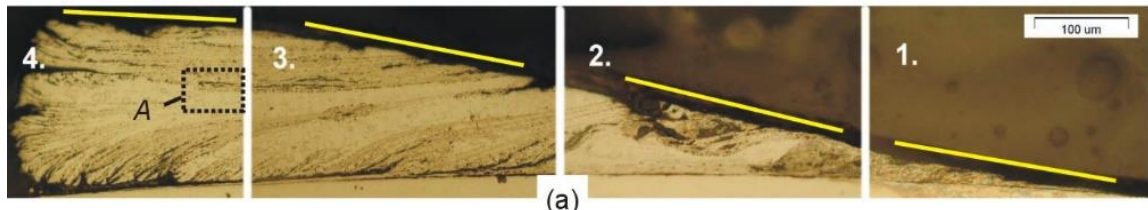

Figure 4 Metallographic photos of the sections of: (a) annealed growth at 650

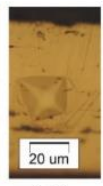

(c)

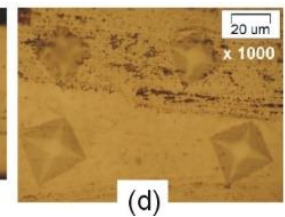

(d) strips after rolling, (d) annealed growth - detail A from figure Figure (a)-4

\section{RESULTS ANALYSIS}

The hardness measured on the surface of the steel strip used for the galling process is $155 \mu \mathrm{HV}$ (Figure 2a). On the other hand, the hardness of the same strip annealed at $650^{\circ} \mathrm{C}$ is $140 \mu \mathrm{HV}$ (Figure $2 \mathbf{b}$ ). This slight difference in value indicates that the tape used for the test was weakly strengthened. For comparison this strip was subjected in the rolling process to a maximum deformation corresponding to the equivalent deformation $\varepsilon$ $=2$. The hardness of the strip so strengthened (Figure 4c) is $215 \mu \mathrm{HV}$ (measurement results are omitted). The build-up after annealing at a temperature of $650^{\circ} \mathrm{C}$ has the initial hardness of the strip i.e. $155 \mu \mathrm{HV}$ (Figure 2a). The structure of the steel build-up formed at $620^{\circ} \mathrm{C}$ is very disturbed. The mechanism of its formation consists in shearing successive layers of material, which are then successively added. The mechanism of its formation consists in shearing subsequent layers of material, which are successively added while creating the built-up edge. The mechanism is closest to the description of [lit]. Very large plastic deformations occur here, causing strengthening and high hardness. Due to the fact that the value of the 
recrystallization temperature decreases with the increase of plastic deformation, a significant decrease in the hardness of the annealed build-up was observed already at the temperature of $400^{\circ} \mathrm{C}$ (Figure 2e). This is related to the heat-activated recovery process. It should be noted that the steel build-up formed at $620^{\circ} \mathrm{C}$ has a hardness of about $370 \mu \mathrm{HV}$ (Figure $\mathbf{2 d}$ ). On the other hand, the same build-up annealed at $600^{\circ} \mathrm{C}$, i.e. at a temperature close to the temperature at which it was formed, has a much lower hardness, about $155 \mu \mathrm{HV}$ (Figures $2 \mathrm{I}, \mathbf{m}$ ), so more than twice less than before the heat treatment process. Such a large difference in the hardness of the build-up is the result of the difference in the dynamics of both processes. The formation of a build-up is a dynamic process. The structural changes of the edge material occur very quickly. After heating, it quickly cools down. As a result of such temperature changes, the structure of build-up becomes supercooled and very disturbed. On the other hand, annealing is a static process. The build-up is first heated to an appropriate temperature, then kept at this temperature for an hour, and then slowly cooled down. As a result of such action, the disturbed growth structure returns to the equilibrium state. Based on the curve from Figure 3, it was established that the build-up recrystallization temperature is $500^{\circ} \mathrm{C}$. Metallographic tests of the build-up after annealing at the temperature of $650^{\circ} \mathrm{C}$ showed that it had a strip structure. Uneven layers are visible in the section of the built-up edge (Figure 4a). Hardness measurements have shown that the individual layers of the built-up edge have different hardness. The light strip in the middle has a hardness of $130 \mu \mathrm{HV}$. The regions below and above this band have a hardness of $190 \mu \mathrm{HV}$. Such a difference in the hardness distribution is caused by uneven recrystallization of the build-up. The light strand has a low hardness because it has been recrystallized to a greater extent. This means that this part of the build-up was more deformed and this band recrystallized faster. As the built-up edge builds up, there is a visible increase in its angle. Figure 4a shows the build-up divided into four sectors. Built-up edge begins in part 1. with a point joining the steel 30 strip with a tool made of NC6 steel, and then builds up over a distance of $250 \mu \mathrm{m}$ at an angle of $9.8^{\circ}$. The built-up edge then reaches a thickness of $33 \mu \mathrm{m}$. In sector 2 , on the section of $315 \mu \mathrm{m}$, there is a clear increase in the angle, which amounts to $13.8^{\circ}$. In this part, the growth reaches a thickness of $100 \mu \mathrm{m}$. In sector 3. the build-up intensity decreases, the angle decreases to $10.9^{\circ}$. On the path of $325 \mu \mathrm{m}$, the built-up thickness increases to $155 \mu \mathrm{m}$. In sector 4 . the angle of rise is small. In the final part, the build-up is $165 \mu \mathrm{m}$ thick. This nature of the changes is mainly caused by the formation of a groove in the tape, in the contact zone of both materials. The second reason for the gradual increase in the thickness of the built-up edge is the curvature of the sample. Both of these causes reduce the normal pressure at the end of the build-up and allow it to expand freely.

\section{CONCLUSIONS}

The conducted tests of annealing of the built-up edge formed as a result of the process of drawing the steel strip 30 in the conditions of semi-hot plastic processing of steel, i.e. at the temperature of $620^{\circ} \mathrm{C}$, allow for the following conclusions.

- $\quad$ From the process temperatures available on the bench: $450,530,620,740$, or $870{ }^{\circ} \mathrm{C}$, in the conditions of drawing the steel 30 strip with the NC6 steel tool in dry friction condition, the greatest tendency to galling, i.e. the formation of the largest build-up was observed at the temperature of $620^{\circ} \mathrm{C}$.

- The recrystallization temperature of the steel build-up resulting from drawing the strip in the conditions of warm metal forming of steel (temperature $620^{\circ} \mathrm{C}$ ) and dry friction is $500^{\circ} \mathrm{C}$.

- The hardness of the build-up formed at $620^{\circ} \mathrm{C}$ is more than 2 times higher than the hardness of the annealed build-up at a temperature of $600{ }^{\circ} \mathrm{C}$.

- $\quad$ Build-up creation is a dynamic process. After heating, there is a rapid cooling down, as a result of which the build-up achieves a very disturbed supercooled structure.

- $\quad$ The energy stored in the supercooled structure of the build-up during annealing at $400^{\circ} \mathrm{C}$ causes a heatactivated recovery process and a $30 \%$ reduction in hardness.

- The built-up has a layered structure: the layers of higher hardness alternate border with the layers of lower hardness. 


\section{ACKNOWLEDGEMENTS}

\section{Studies were funded by project granted by Warsaw University of Technology under the program Excellence Initiative: Research University (ID-UB, 504/04496/1104/45.010502).}

\section{REFERENCES}

[1] EGOROV S., OLEJNIK A., KAPITANOV A., ALEXANDROV I. Buildup forming on tools at mechanical metal surface-hardening. International Journal of Advanced Manufacturing Technology. 2021.

[2] GÅARD A., KRAKHMALEV P., BERGSTRÖM J. Wear mechanisms in galling: Cold work tool materials sliding against high-strength carbon steel sheets. Tribology Letters. 2009, vol. 33, no. 1, pp. 45-53.

[3] BUDINSKI K.G., BUDINSKI S.T. Interpretation of galling tests. Wear. 2015, vol. 332-333, pp. 1185-92.

[4] HEINRICHS J., OLSSON M., JACOBSON S. Initiation of Galling in Metal Forming: Differences between Aluminium and Austenitic Stainless Steel Studied in Situ in the SEM. Tribology Letters. 2013, vol. 50, no. 3, pp. 431-8.

[5] GÅR̃D A., KRAKHMALEV P., BERGSTRÖM J., HIRVONEN GRYTZELIUS J., ZHANG H.M. Experimental study of the relationship between temperature and adhesive forces for low-alloyed steel, stainless steel, and titanium using atomic force microscopy in ultrahigh vacuum. Journal of Applied Physics. 2008, vol. 103, no. 12.

[6] ENGEL U. Tribology in microforming. Wear. 2006, vol. 260, no. 3, pp. 265-73.

[7] JEON J., BRAMLEY A.N. A friction model for microforming. International Journal of Advanced Manufacturing Technology. 2007, vol. 33, no. 1-2, pp. 125-9.

[8] PRESZ W. Contact phenomena in micro-blanking. International Journal of Material Forming. 2008, vol. 1, no. SUPPL. 1, pp. 470-474.

[9] WANG W., ZHENG X., HUA M., WEI X. Influence of surface modification on galling resistance of DC53 tool steel against galvanized advanced high strength steel sheet. Wear. [online]. 2016, vol. 360-361, pp. 1-13. Available from: https://doi.org/10.1016/j.wear.2016.04.021.

[10] GÅRRD A., KRAKHMALEV P., BERGSTRÖM J. Influence of tool steel microstructure on origin of galling initiation and wear mechanisms under dry sliding against a carbon steel sheet. Wear. 2009, vol. 267, no. 1-4, pp. 387-93.

[11] COCKS M. Interaction of Sliding Metal Surfaces. Journal of Applied Physics. 1962, vol. 33, no. 7, pp. $2152-61$.

[12] PODGORNIK B., JERINA J. Surface topography effect on galling resistance of coated and uncoated tool steel. Surface and Coatings Technology. [online]. 2012, vol. 206, no. 11-12, pp. 2792-800. Available from: https://doi.org/10.1016/j.surfcoat.2011.11.041.

[13] PRESZ W., CACKO R. Ultrasonic assisted microforming. In: METAL 2017 - 26th International Conference on Metallurgy and Materials. Brno: Tanger, 2017, pp. 521-6.

[14] PRESZ W. Dynamic effect in ultrasonic assisted micro-upsetting. In: AIP Conference Proceedings. [online]. 2018, p. 100012. Available from: https://doi.org/10.1063/1.5034952.

[15] DAURE J.L., CARRINGTON M.J., MCCARTNEY D.G., STEWART D.A., SHIPWAY P.H. Measurement of friction in galling testing - An example of its use in characterising the galling behaviour of hardfacings at ambient and elevated temperature. Wear. [online]. 2021, vol. 476, p. 203736. Available from: https://doi.org/10.1016/j.wear.2021.203736.

[16] HUMMEL S.R., PARTLOW B. Comparison of threshold galling results from two testing methods. Tribology International. 2004, vol. 37, no. 4, pp. 291-5.

[17] ROGERS S.R., BOWDEN D., UNNIKRISHNAN R., SCENINI F., PREUSS M., STEWART D., et al. The interaction of galling and oxidation in 316L stainless steel. Wear. [online]. 2020, vol. 450-451, p. 203234. Available from: https://doi.org/10.1016/j.wear.2020.203234.

[18] HEINRICHS J., OLSSON M., JACOBSON S. New understanding of the initiation of material transfer and transfer layer build-up in metal forming-In situ studies in the SEM. Wear. [online]. 2012, vol. 292-293, pp. 61-73. Available from: https://doi.org/10.1016/j.wear.2012.05.032.

[19] QARNI M.J., ROSOCHOWSKI A., BOCZKAL S. Warm deformation behaviour of UFG CP-Titanium produced by I-ECAP. IOP Conference Series: Materials Science and Engineering. 2017, vol. 194, p. 012038. 